\title{
IS THERE A SAFE LIMIT OF DELAY FOR EMERGENCY CAESAREAN SECTION IN GHANA? RESULTS OF ANALYSIS OF EARLY PERINA- TAL OUTCOME
}

\author{
S. A. OPPONG ${ }^{1}$, M. G. TUULI ${ }^{2}$, J. D. SEFFAH ${ }^{1}$ and R.M.K. ADANU ${ }^{3}$ \\ ${ }^{1}$ Department of Obstetrics and Gynaecology, University of Ghana Medical School, Accra, Ghana, ${ }^{2}$ Division of \\ Maternal Fetal Medicine, Department of Obstetrics and Gynaecology, Washington University School of Med- \\ icine, St Louis, Missouri, USA, ${ }^{3}$ School of Public Health, University of Ghana, Accra, Ghana
}

DOI: http://dx.doi.org/10.4314/gmj.v48i1.4

Corresponding Author: Dr. Samuel Antwi Oppong

Email:wak72@yahoo.com

Conflict of Interest: None declared

\section{SUMMARY}

Objective: To determine the limits of delaying caesarean section in a busy obstetric unit in a developing country setting that is not associated with neonatal survival.

Methods: Retrospective cohort study of emergency cesarean sections. Indications were sub-divided into imminent threat and no imminent threat to fetal wellbeing. The primary outcomes was a composite measure of adverse perinatal outcome including stillbirth, 5minute Apgar score $<7$ and neonatal intensive care unit admission. Effect of decision-to-delivery interval on perinatal outcomes was evaluated using KaplanMeier survival analysis.

Results: 495 women met inclusion criteria (142 'imminent threat' group, 353 'no imminent threat' group). The median decision-to-delivery interval was significantly shorter in the 'imminent threat' group $(2.25$ [95\% CI 1.38 - 5.83] versus 3.42 [95\% CI 1.83 - 5.85] hours, $\mathrm{p}<0.001$ ). Only $1.7 \%$ and $12.7 \%$ sections were performed within 30 minutes and 1 hour, respectively. Risk of the composite outcome was significantly higher in the 'imminent threat group (46.5\% versus $31.2 \%$, $\mathrm{RR}=1.49$ [95\% CI 1.18 - 1.89], $\mathrm{p}=0.001$ ). A 95\% probability of 'live intact' survival occurred at $1 \mathrm{hr}$ and $2 \mathrm{hrs}$ respectively, for the imminent threat and the no imminent threat groups

Conclusion: Increasing decision-to-delivery interval is associated with higher risk of adverse perinatal outcomes, but a $95 \%$ live intact survival can be achieved if the delivery occurs within 2 hours.

Key words: Limits of delay, caesarean section, Ghana, perinatal outcome

\section{INTRODUCTION}

Decision-to-delivery interval of emergency caesarean section is considered an important determinant of perinatal outcome and has become a measure of standard of care. Both the Royal College of Obstetricians and Gynaecologists and the American College of Obstetricians and Gynecologists recommended a decision-todelivery interval of less than 30 minutes for emergency caesarean sections. ${ }^{1,2}$ In an attempt to objectively define cases requiring immediate delivery Lucas et al. proposed a grading system based on the clinical state of the mother and baby. ${ }^{3}$

Data on the effect of decision-to-delivery interval on neonatal outcome is limited, with data from developing countries even more sparse. ${ }^{4,5,6,7}$ While the 30-minute recommendation for emergency caesarean sections may be feasible in the large modern obstetric units of developed countries, the same cannot be said of the busy and often congested maternity units in many developing countries. In these units, obstetricians are often confronted with the difficult task of prioritizing different pressing indications for caesarean delivery based on perceived threat to maternal or fetal wellbeing. Unfortunately, the evidence base for such decision making is limited.

The objective of this study is to determine the limits of delaying caesarean delivery in a busy obstetric unit in a developing country setting that would not adversely affect perinatal survival.

\section{MATERIALS AND METHODS}

This is a retrospective cohort study involving patients who had emergency caesarean sections at the Maternity unit of Korle-Bu Teaching Hospital in Accra, Ghana, between April 1, 2008 and July 31, 2008. The unit performs about 12,000 deliveries a year and 12 to 15 caesarean sections each day using one operating theatre for both elective and emergency cases. The obstetricians determine the order in which deliveries are performed, based on perceived acuity of the prevailing threat to maternal and fetal wellbeing. 
All women with singleton pregnancies at 34 weeks' gestation or more who underwent emergency caesarean sections during the study period were eligible.

Emergency caesarean sections were defined as unscheduled caesarean deliveries performed before or during labour and designated as such in the operative report by the surgeon. Multiple gestations and confirmed intra-uterine fetal death at the time the decision was made to perform the caesarean section were excluded. An attempt was made to retrieve the medical charts of all eligible patients.

Information on demographic characteristics, antenatal care, labour course and indication for caesarean section were collected. The decision-to-delivery interval, defined as the duration from the time the decision was made to the time the baby was delivered by caesarean section (in minutes) was recorded for each patient. These were then converted to hours for all analysis.

The indications for emergency caesarean section were sub-divided into two groups based on whether or not there was an imminent threat to fetal survival at the time the decision was made to perform the caesarean section. Indications in the 'imminent threat group' included fetal distress, cord prolapse, abruptio placenta and placenta previa with heavy bleeding.

Fetal distress was diagnosed by presence of abnormal fetal heart rate pattern, determined by intermittent auscultation, and fresh meconium in the liquor. Indications in the 'no imminent threat group' were cephalopelvic disproportion (CPD), failure of progress of labour, eclampsia/severe preeclampsia remote from delivery, malpresentation in labour, two or more prior caesarean sections in labour, failed induction of labour and prolonged rupture of membranes.

The primary outcome was a composite measure of adverse perinatal outcomes including stillbirth, 5-minute Apgar score $<7$ and neonatal intensive care unit (NICU) admission. This was an arithmetic sum and the components were not weighted. Secondary outcomes were the individual components of the composite outcome.

Demographic and pregnancy characteristics in the 'imminent threat' and 'no imminent threat' groups were compared. Rates of the composite and individual adverse perinatal outcomes, relative risks (RR) and 95 $\%$ confidence intervals (CI) were calculated. Normally distributed variables (verified by the Kolmogorovsmirnov test) were compared using the student's t test. The Mann-Whitney test was used for variables that were not normally distributed. Categorical variables were compared using the chi-square test.
The effect of decision-to-delivery interval on perinatal outcomes was evaluated using Kaplan-Meier survival analysis.

Differences between the survival functions of the groups were assessed using the Log-rank test. Tests with $\mathrm{p}<0.05$ were considered statistically significant. Statistical analysis was performed using STATA version 10.0 (Stata Corp., College Station, TX).

\section{RESULTS}

A total of 4,246 deliveries occurred during the fourmonth study period. Of these, $1,189(28.0 \%)$ were by caesarean sections and $951(80 \%)$ of these were emergency sections. In all, 495 women met inclusion criteria and had complete records for analysis. Of these, $71.3 \%(353 / 495)$ were in the 'no imminent threat' group while $28.7 \%(142 / 495)$ were in the 'imminent threat' group. The most common indication for caesarean section in the 'imminent threat' group was fetal distress which accounted for $80.3 \%$ of cases.

Cephalopelvic disproportion/failure to progress $(40.8 \%)$ and eclampsia/severe preeclampsia remote from delivery $(34.9 \%)$ accounted for the majority of cases in the 'no imminent threat' group. Characteristics of the study population are shown in Table 1. The 'imminent threat' and 'no imminent threat' groups were similar with regards to these characteristics except for a slightly higher proportion of parturients in the 'imminent threat' group receiving prenatal care at the teaching hospital $(28.6 \%$ versus $19.0 \%, \mathrm{p}=0.02)$. The median decision-to-delivery interval (interquartile range) for the entire cohort was 3.00 (1.72 - 5.01) hours.

The interval was significantly shorter in the 'imminent threat' compared to the 'no imminent threat' group (median 2.25 [1.38 - 5.83] versus 3.42 [1.83 - 5.85] hours, $\mathrm{p}<0.001)$. Table 2 shows the distribution of decision-to-delivery intervals for emergency caesarean sections for the study cohort. Only $1.7 \%$ and $12.7 \%$ of emergency cesarean sections were performed within 30 minutes and 1 hour, respectively. At 5 hours, $31.8 \%$ of emergency caesarean sections (including $13.3 \%$ of those in the 'imminent threat' group) were not yet performed. The decision-to-delivery interval was $>8$ hours in $11.0 \%$ of all cases; $5.7 \%$ in the 'imminent threat' group and $13.0 \%$ in the 'no imminent threat' group.

Table 3 shows perinatal outcomes for the emergency caesarean sections in our cohort. The composite adverse perinatal outcome (still birth, or APGAR $<7$ or NICU admission) occurred in $35.6 \%$ of cases (176/495). 
Risk of this outcome was significantly higher in the 'imminent threat' group compared to the 'no imminent threat' group (46.5\% versus $31.2 \%, \mathrm{RR}=1.49[95 \%$ CI $1.18-1.89$ ], $\mathrm{p}=0.001)$.

Table 1 Baseline characteristics of women undergoing emergent caesarean sections

\begin{tabular}{|c|c|c|c|c|}
\hline Parameter & All $\quad(\mathrm{N}=495)$ & $\begin{array}{l}\text { 'Imminent threat' } \\
\text { Group } \\
(\mathrm{n}=142)\end{array}$ & $\begin{array}{lr}\text { 'No } & \text { imminent } \\
\text { threat' } & \text { group } \\
(\mathbf{n}=353) & \\
\end{array}$ & $\mathbf{P}$ \\
\hline Maternal age (yrs), median (IQR) & $29(25-34)$ & $29(25-34)$ & $30(26-34)$ & 0.48 \\
\hline Married, n (\%) & $432(90.4)$ & $125(91.9)$ & $307(89.8)$ & 0.47 \\
\hline Primiparous, n(\%) & $303(38.8)$ & $83(58.4)$ & $220(62.3)$ & 0.42 \\
\hline Prenatal care attendant, $\mathrm{n}(\%)$ & $396(80.3)$ & $114(81.4)$ & $282(79.9)$ & 0.70 \\
\hline Prenatal care at Korle-bu, n (\%) & $107(21.8)$ & $40(28.6)$ & $67(19.0)$ & 0.02 \\
\hline Birth weight (grams), median (IQR) & $3100(2700-3500)$ & $3100(2600-3550)$ & $3100(2700-3500)$ & 0.81 \\
\hline $\begin{array}{l}\text { Indications for caesarean section, n (\%) } \\
\text { Fetal distress } \\
\text { Cord prolapse } \\
\text { Abruption } \\
\text { Bleeding previa } \\
\text { CPD/Failure to progress } \\
\text { Severe preeclampsia } \\
\text { Eclampsia } \\
\text { Prolonged rupture } \\
\text { Malpresentation } \\
\text { Failed induction } \\
\text { Two prior sections in labor } \\
\text { Other }\end{array}$ & $\begin{array}{l}114(23.0) \\
6(1.2) \\
18(3.6) \\
4(0.8) \\
144(29.1) \\
99(20.0) \\
24(4.8) \\
23(4.6) \\
15(3.0) \\
13(2.6) \\
10(2.0) \\
25(5.1)\end{array}$ & $\begin{array}{l}114(80.3) \\
6(4.2) \\
18(12.7) \\
4(2.8) \\
- \\
- \\
- \\
- \\
- \\
- \\
- \\
-\end{array}$ & $\begin{array}{l}- \\
- \\
- \\
- \\
144(40.8) \\
99(28.1) \\
24(6.8) \\
23(6.5) \\
15(4.3) \\
13(3.7) \\
10(2.8) \\
25(7.1)\end{array}$ & - \\
\hline
\end{tabular}

$\mathrm{CPD}=$ Cephalopelvic disproportion, $\mathrm{IQR}=$ Interquartile range

Table 2 Distribution of decision-to-delivery interval for emergent caesarean sections

\begin{tabular}{|c|c|c|c|}
\hline \multirow[b]{2}{*}{$\begin{array}{l}\text { Interval } \\
\text { (hours) }\end{array}$} & \multicolumn{3}{|c|}{ Number (\%) } \\
\hline & $\begin{array}{l}\text { All } \\
(\mathrm{N}=495)\end{array}$ & $\begin{array}{l}\text { 'Imminent threat' } \\
\text { Group } \\
(\mathrm{n}=142)\end{array}$ & $\begin{array}{lr}\text { 'No } & \text { imminent } \\
\text { threat' } & \text { group } \\
(\mathbf{n}=353) & \\
\end{array}$ \\
\hline $0-0.5$ & $8(1.7)$ & $4(2.8)$ & $4(1.2)$ \\
\hline $0-1$ & $61(12.7)$ & $27(19.2)$ & $34(10.0)$ \\
\hline 1-2 & $95(19.8)$ & $33(23.4)$ & $62(18.3)$ \\
\hline $2-3$ & $85(17.7)$ & $31(22.0)$ & $54(15.9)$ \\
\hline $3-4$ & $65(13.5)$ & $17(12.1)$ & $48(14.2)$ \\
\hline 4-5 & $54(11.3)$ & $14(9.9)$ & $40(11.8)$ \\
\hline $5-6$ & $28(5.8)$ & $8(5.7)$ & $20(5.9)$ \\
\hline 6-7 & $20(4.2)$ & $1(0.7)$ & $19(5.6)$ \\
\hline $7-8$ & $20(4.2)$ & $2(1.4)$ & $18(5.3)$ \\
\hline$>8$ & $53(11.0)$ & $8(5.7)$ & $44(13.0)$ \\
\hline
\end{tabular}

Table 3 Effect of acuity of the indication of emergency caesarean sections on neonatal outcomes

\begin{tabular}{|c|c|c|c|c|c|}
\hline Outcomes & $\begin{array}{l}\text { All } \\
(\mathrm{N}=495)\end{array}$ & $\begin{array}{l}\text { 'Imminent } \\
\text { threat' Group } \\
(\mathrm{n}=142)\end{array}$ & $\begin{array}{lr}\text { 'No } & \text { imminent } \\
\text { threat' } & \text { group } \\
(\mathrm{n}=353) & \\
\end{array}$ & $\begin{array}{l}\text { Relative } \quad \text { Risk } \\
(95 \% \text { CI })\end{array}$ & $\mathbf{P}$ \\
\hline $\begin{array}{l}\text { Composite adverse neonatal out- } \\
\text { come, } n(\%)\end{array}$ & $176(35.6)$ & $66(46.5)$ & $110(31.2)$ & $1.49(1.18-1.89)$ & 0.001 \\
\hline NICU admission, $\mathbf{n}(\%)$ & $142(30.1)$ & $56(41.5)$ & $86(25.5)$ & $1.63(1.24-2.13)$ & $<0.001$ \\
\hline 5-minute Apgar score < 7, n (\%) & $148(31.6)$ & $54(40.9)$ & $94(27.9)$ & $1.47(1.12-1.92)$ & 0.006 \\
\hline
\end{tabular}


For the individual components of the composite outcome, NICU admission and 5-minute Apgar score $<7$ were each significantly more common among the 'imminent threat' group (41.5\% versus $25.5 \%, \mathrm{RR}=1.63$ [95\% CI $1.24-2.13$ ], $\mathrm{p}<0.001$ and $40.9 \%$ versus 27.9 $\%, \mathrm{RR}=1.47$ [95 \% CI $1.12-1.92$ ], $\mathrm{p}=0.006$, respectively). Twenty six stillbirths occurred while awaiting caesarean delivery; 10 in the 'imminent threat' group and 16 in the 'no imminent threat' group. Although the stillbirth rate was higher in the 'imminent threat' group, the difference did not reach statistical significance $(7.0 \%$ versus $4.5 \%, \mathrm{RR}=1.55$ [95\% CI 0.72 $3.34], \mathrm{p}=0.26)$.

The decision-to-delivery interval at which the probability of 'intact' survival fell to $50 \%$ (the median survival time) was 5 hours for the 'imminent threat' group and $>8$ hours for the 'no imminent threat' group. Similarly, a $95 \%$ probability of live 'intact' survival occurred at a decision-to-delivery interval of 1 hour in the 'imminent threat' group and 2 hours in the 'no imminent threat' group.

Figure 1 shows the Kaplan-Meier survival curves for live 'intact' survival as a function of decision-todelivery interval. A live 'intact' neonate was defined as a live neonate with 5-minute Apgar $\geq 7$ and no NICU admission. The probability of live 'intact' survival decreased with increasing decision-to-delivery interval for all emergency caesarean sections. The decrease was significantly more rapid among the 'imminent threat' group compared to the 'no imminent threat' group (Log-rank test $\mathrm{p}<0.001$ ).

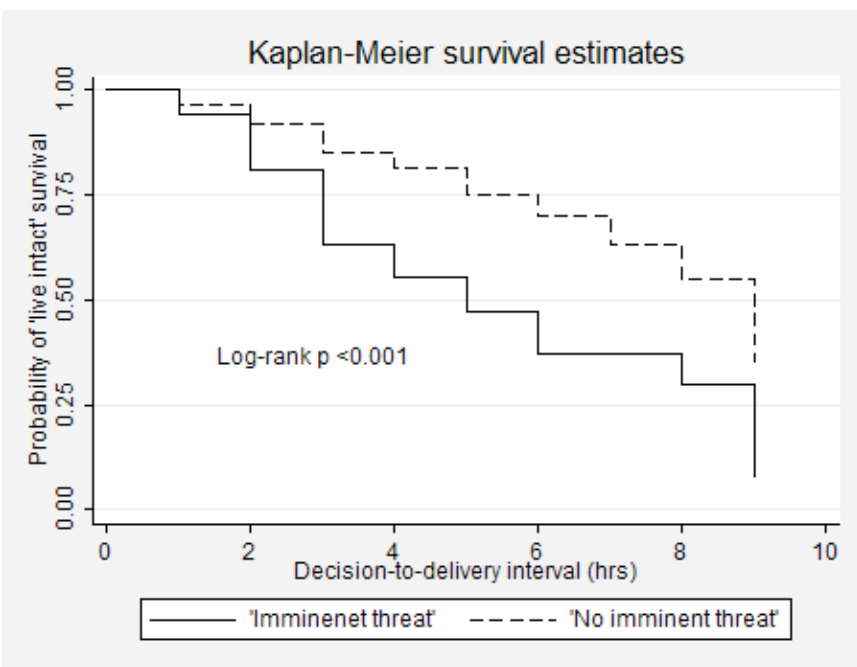

Figure 1 Kaplan-Meier survival curves for live 'intact survival as a function of decision-to-delivery interval

Figure 2 shows the Kaplan-Meier survival curves for live 'intact' survival for the three leading indications for emergency caesarean sections. Of these indications, fetal distress was associated with the steepest decline in live 'intact' survival with increasing decision-todelivery interval (log-rank $\mathrm{p}<0.001)$. A 95\% probability of "live intact" survival occurred at $1 \mathrm{hr}$ in the fetal distress group, $2 \mathrm{hrs}$ in the CPD group and $3 \mathrm{hrs}$ in the severe pre-eclampsia group.

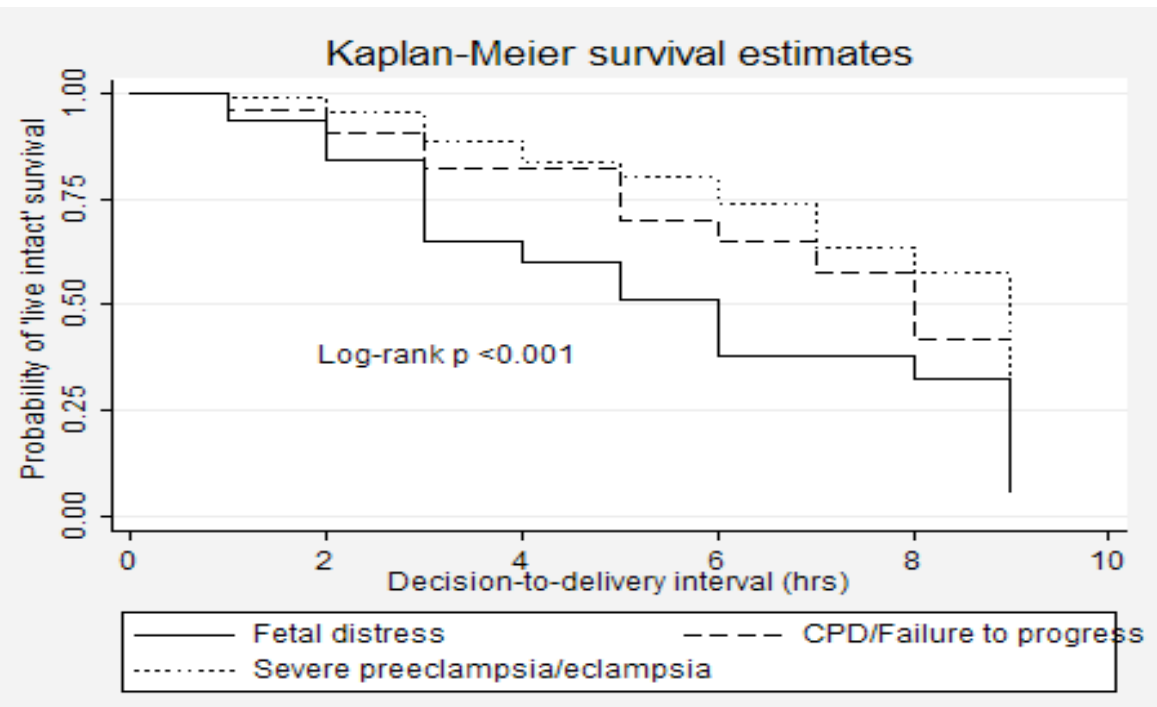

Figure 2 Kaplan-Meier survival curves for live 'intact' survival for the three leading indications for emergency caesarean sections. 


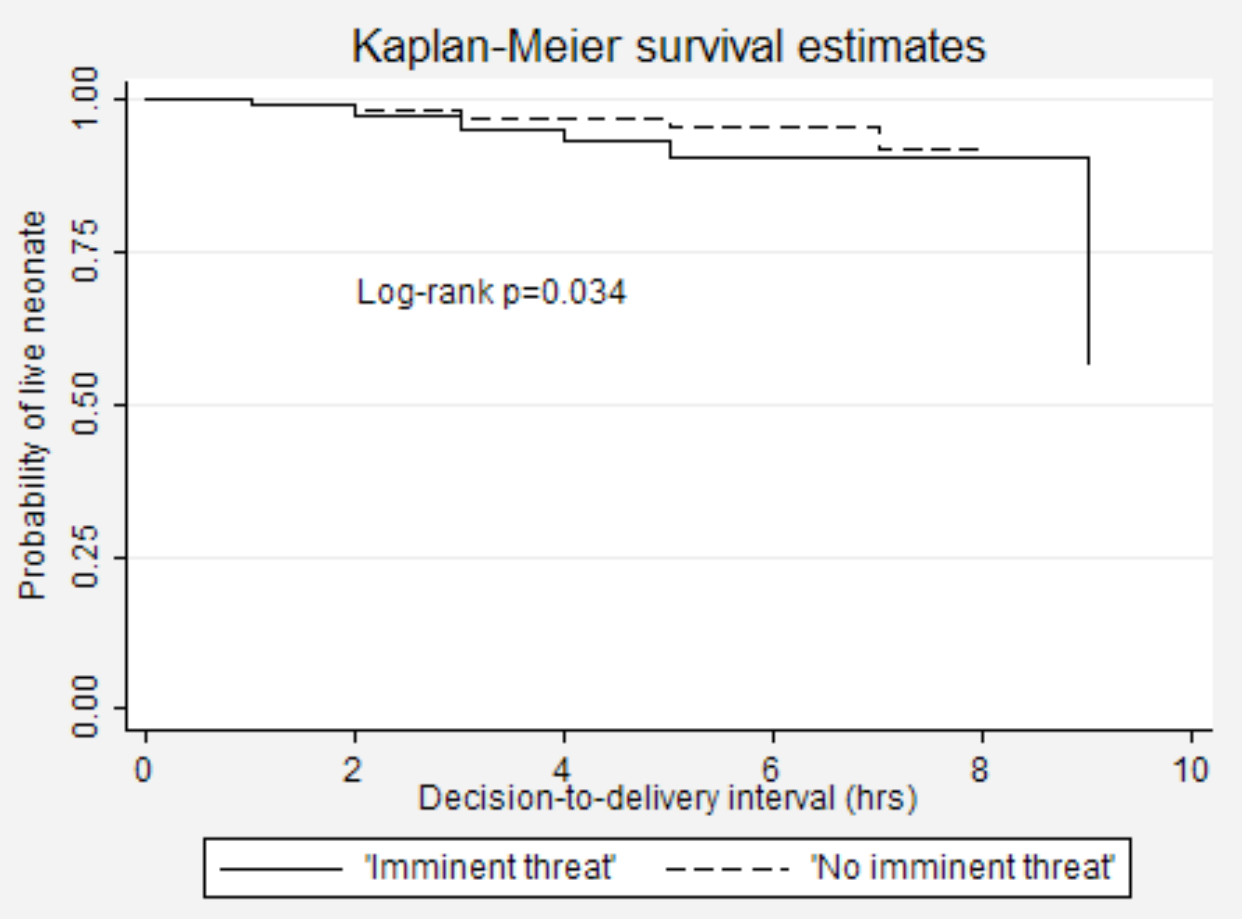

Figure 3 The effect of decision-to-deliver interval on stillbirth

The effect of decision-to-delivery interval on stillbirth is shown in Figure 3. The decline in probability of a live neonate decreased significantly more steeply among the 'imminent threat' compared to the 'no imminent threat' group (Log-rank test $\mathrm{p}=0.034)$. Of note, there was no stillbirth in either group when the decision-to-delivery interval was $<1$ hour.

\section{DISCUSSION}

Delays in performing caesarean delivery are inevitable especially in resource-poor setting and are a source of stress for the neonate and the whole obstetric unit. Current standard of care focuses on the effect of decisionto-delivery interval on the neonatal outcome. While the 30 minutes standard may be a good guide, this may not be feasible in all settings, especially the busy obstetric units in resource poor countries. It is, therefore, important to determine realistic limits of delay that is not associated with adverse perinatal outcome.

This study evaluated the effect of delaying emergency caesarean delivery on adverse perinatal outcomes in a developing country setting. We also determined the limits of delay for each indication that does not adversely affect perinatal outcome. We used a composite perinatal outcome consisting of stillbirth, NICU admission and 5-minute Apgar score $<7$. The components of this composite outcome are on a continuum of adverse perinatal outcomes. Our data confirms that adverse perinatal outcome increases with increasing decision- to-delivery interval. Although the median interval in the imminent threat group was significantly shorter than in the 'no imminent threat' group, it was still much above the 30 minutes currently recommended. ${ }^{1,2}$

However, there was a $95 \%$ probability of live 'intact' survival at a decision-to-delivery interval of 1 hour in the 'imminent threat' group and 2 hours in the 'no imminent threat' group. We also noted that there was no stillbirth in either group when the decision-to-delivery interval was $<1$ hour. This provides useful information for programmes aimed at reducing stillbirths and adverse perinatal outcomes.

The use of survival analysis in this study is innovative and to our knowledge is the first report of its use in the evaluation of decision-to-delivery intervals and perinatal outcomes. The survival probabilities from this analysis provide an objective means of predicting fetal outcome and therefore prioritizing deliveries based on indication.. Our results differ significantly from those of similar studies in developed country settings. In a retrospective cohort of 109 emergency 'crash' caesarean sections in a level three German hospital, all deliveries were performed within 30 minutes, with a median decision-to-delivery interval of 10 minutes. ${ }^{8}$ The indications in that cohort were similar to those in our 'imminent threat' group. Even with such rapid delivery, increasing decision-to-delivery intervals were associated with lower Apgar scores. In contrast, a study from 
the United Kingdom showed that fewer than $40 \%$ of intrapartum caesarean deliveries for fetal distress were achieved within 30 minutes. ${ }^{9}$

There was no evidence that a decision-to-delivery interval of up to 120 minutes was detrimental to the neonate unless delivery was a 'crash' caesarean section. One of the largest studies to date involving 13 academic centers in the United States found that $65 \%$ of caesarean sections performed for emergency indications occurred within 30 minutes. ${ }^{10}$ paradoxically, measures of newborn compromise were significantly higher when delivery commenced within 30 minutes. This was attributed to the underlying factors that necessitated the expedited delivery in those cases.

Studies from developing countries on decision-todelivery intervals are sparse, but those results are more comparable to ours. Onah et al. evaluated 224 consecutive emergency caesarean sections in two Nigerian hospitals and reported that none was done within the recommended 30-minute interval. ${ }^{11}$ In contrast to our results; however, they found no significant correlation between the decision-to-delivery interval and perinatal outcome.

They concluded that the recommended 30-minute decision-to-delivery interval is not feasible in Nigeria and that the delays observed may not be associated with adverse neonatal outcomes. What their study failed to demonstrate is the relation between decision- todelivery interval and the composite of these individual outcomes. Neonatal wellbeing, in our opinion, is best demonstrated by the absence of the composite outcome and not just the individual outcomes, hence the use of live 'intact' neonate in our study. The probability of live 'intact' neonate varied significantly with the decision-to-delivery interval in our study.

Some investigators have attempted to elucidate the reasons for delays in performing emergency caesarean sections. Sayegh et al, identified the major causes of delay as waiting for the operating room, waiting for the anaesthetist, multiple attempts at regional anaesthesia, and waiting for the paediatrician. ${ }^{12}$ Non availability of operating room staff and complications of anaesthesia have also been cited in some studies. ${ }^{13}$ In our unit, obstetricians, anaesthetists and operating room staff are physically present in the labour and delivery unit. Therefore, lack of operating room access appears to be the main cause of delay. Some have advocated for a more efficient use of existing operating facilities. Helmy et al. found that the introduction of time sheets reduced delays and resulted in a $70 \%$ increase in the number of emergency caesarean sections performed under 30 minutes. 4
Introduction of a similar practice could improve efficiency in our unit. We acknowledge our limitations. The retrospective design lends itself to issues of missing data and information bias. The classifications of caesarean section as emergency as well as the individual indications were dependent on accurate documentation in patients' charts. If this was inaccurate, our results could have been affected. However, there is no indication that any such inaccuracy was biased towards one group.

We used the 5-minute Apgar score $<7$ as a proxy for fetal acidaemia. While we acknowledge that cord blood gases would have been a better measure, they are not available in the study setting. The diagnosis of fetal distress was by intermittent auscultation of the fetal heart beat and presence of fresh meconium in the amniotic fluid. While intermittent auscultation has been shown to be equivalent to continuous electronic fetal monitoring in low risk pregnancies, its accuracy for diagnosing fetal distress in the setting of this study is unknown. ${ }^{14}$

In addition, the categorization of indications for emergency caesarean section into the two groups is somewhat arbitrary. However, it reflects the reality obstetricians face in prioritizing caesarean sections in this setting and therefore is of practical value. Finally, we only evaluated fetal outcomes. We acknowledge that maternal wellbeing is important and should be taken into consideration when prioritizing caesarean sections.

\section{CONCLUSION}

In conclusion, this survival analysis in a developing country setting confirms that increasing delay to perform emergency caesarean sections is associated with increased risk of adverse perinatal outcomes. The unacceptably long delays from decision-to-delivery and the associated high rates of adverse perinatal outcomes call for remedial measures. However, a 95\% 'live intact' survival can be attained if all emergency caesarean deliveries occur within 2 hours of such decision making. This data provides realistic targets for programmes aimed at reducing adverse outcomes in resource poor settings.

\section{REFERENCES}

1. Royal College of Obstetricians and Gynaecol ogists Report of Joint Working Group: Organization of standards for maternity services. RCOG Press, London 2005

2. American College of Obstetricians and Gynecologists Committee on Professional Standards: In Standards for obstetrics and gynecology services; $7^{\text {th }}$ ed Washington DC, 1989 
3. Lucas DN, Yeltis SM, Kinsella SM, Holdcroft A, May AE, Wee M, et al. Urgency of caesarean section: a new classification. J R Soc Med 2000; 93: 346-50

4. Helmy WH, Joloaso AS, Ifaturoti OO, Affy SA, Jones $\mathrm{MH}$. The decision-to-delivery interval for emergency caesarean section: is the 30 mins a realistic target? BJOG 2002; 109: 505-508.

5. Schauberger CW, Chauhan SP. Emergency caesarean section and the 30 minutes rule. Definitions. Am J Perinatol 2009; 26: 221-226

6. Lagrew DC, Bush MC, McKeown AM, Lagrew NG. Emergent (crash) caesarean delivery: Indications and outcomes. Am J Obstet Gynecol 2006; 194: 1638-43

7. Dunphy BC, Ribinson JN, Sheil OM, Nichols JSD, Gillmer MDG. Caesarean section for fetal distress, the interval from decision to delivery and relative risk of poor neonatal condition. J Obstet Gynecol 1991; 11: 241-244

8. Hillemanns P, Strauss A, Hasbargen U, Schulze A, Genzel-Boroviczeny O, Weninger E, et al.: Crash emergency cesarean section: decision-to-delivery interval under $30 \mathrm{~min}$ and its effect on Apgar and umbilical artery pH. Arch Gynecol Obstet 2005; 273: 161-165.

9. MacKenzie, I.Z. and I. Cooke, What is a reasonable time from decision-to-delivery by caesarean section? Evidence from 415 deliveries. BJOG, 2002. 109(5): p. 498-504.

10. Bloom SL, Leveno KJ, Spong CY, Gilbert S, Hauth $\mathrm{JC}$, Landon MB, et al.: Decision-to-incision times and maternal and infant outcomes. Obstet Gynecol 2006; 108: 6-11

11. Onah HE, Ibeziako N, Umezulike AC, Effetie ER, Ogbuokiri CM: Decision - delivery interval and perinatal outcome in emergency caesarean sections. $J$ Obstet Gynaecol 2005; 25: 342-346.

12. Sayegh I, Dupius O, Clement HJ, Rudigoz RC. Evaluating the decision-to-delivery interval in emergency caesarean sections. Eur J Obstet \& Gynecol Reprod Biol 2004; 116: 28-33.

13. Spencer MK, MacLennan AH. How long does it take to deliver a baby by emergency caesarean section? Aust N Z Obstet Gynaecol 2001; 41(1): 7-

14. Sandmire HF: Whither electronic fetal monitoring? Obstet Gynecol 1990; 76: 1130-1134. 